\title{
A Case for Differentiated Grades
}

\author{
Kenneth D. Royal ${ }^{1}$ - Thomas R. Guskey ${ }^{2}$
}

Published online: 18 April 2015

(C) International Association of Medical Science Educators 2015

\section{Commentary}

The recent court ruling in favor of Case Western Reserve University that denied a medical degree to a student based on a lack of professionalism shows the clear need for differentiated grading in medical education. In the Ohio case [1], a threejudge panel concluded that evaluations regarding professionalism are academic judgments that fall within the purview of the degree-granting institution. Thus, medical students with strong academic records based on assessments of their medical knowledge and skills may legally fail a course, fail a program, or otherwise be denied a degree based on unprofessional conduct.

Although this case attracted great attention, the situation is not unusual. Stories abound of students who make outstanding grades and put forth maximum effort, but are lacking in the area of professional behavior. As Chen [2] points out, many medical school faculty members would like to fail students who exhibit extremely unprofessional behavior, but often believe such a decision would be indefensible given the student's adequate performance on examinations of medical knowledge and skills. Other faculty members attempt to address this issue by allocating sufficient weight to professionalism indictors in the grade so that students with high assessment scores, but poor professionalism, could not receive a passing course grade. In this article, we discuss an alternative solution through differentiated grading that is designed to make grades more meaningful, accurate, and educationally sound.

Kenneth D. Royal

kdroyal2@ncsu.edu

Thomas R. Guskey

guskey@uky.edu

1 North Carolina State University, Raleigh, NC, USA

2 University of Kentucky, Lexington, KY, USA

\section{Amalgamated Versus Differentiated Grades}

Medical educators would consider it ridiculous to combine measures of a patient's height in inches, weight in pounds, calorie intake per day, and number of minutes spent exercising each day in a single "grade" representing the patient's physical condition. These are different measures, gathered through different means and expressed in different units. Although these measures are often related, they represent very different data on the patient's physical condition. Combining these measures into a single grade makes no sense. Yet, every day, medical educators combine evidence of students' knowledge and skills, behavior, and professionalism, each measured in different ways and expressed in different units, into a single grade representing students' performance. This, too, makes no sense.

Most medical educators agree that the purpose of a grade is to describe the performance of a student in achieving the learning goals set forth for a given course. However, judgments about factors such as attitudes and behaviors are typically more subjective, and faculty may feel less comfortable defending such marks. For this reason, many medical educators have long resisted the notion of differentiated grades. We contend that the continued use of an amalgamated grade provides far more drawbacks than differentiated grades. More specifically, amalgamated grades cause problems in regard to making valid inferences and calculating class ranks and are, in fact, more difficult to defend.

Perhaps the most significant problem with amalgamated grades is the meaning of the grade diminishes completely when the context of the grading scenario is removed. For example, faculty and students alike may generally understand what a grade represents when considering how the grade was determined in a particular course because it was outlined in the syllabus. However, others using these grades to judge student 
performance may not have access to this type of information and are unlikely to know what specific criteria the instructor used for assessing performance, the weighting schema used to differentiate important factors such as knowledge, skills, attitudes and behaviors, and how students performed in each of the areas they may care about. Differentiated grades immediately paint a clearer, more thorough, and valid picture of students' performance.

Consequential validity $[3,4]$ refers to the positive/negative and intended/unintended consequences that may result from the inferences made about a set of scores or grades. For example, when individuals and groups (e.g., residency programs, employers, etc.) make inferences about scores that are based on amalgamated grades, there is a significant risk that the inferences made about a student are distorted. This distortion violates a "social contract" between the faculty assigning the grades and the consumers of this information. Differentiated grades, on the other hand, remove the ambiguity associated with grades and provide consumers a clear picture of student performance.

Another problem associated with amalgamated grades involves the calculation of class ranks. At most institutions, class rankings are derived solely from achievement criteria such as grade point averages (GPA). At best, these calculations contain only limited information about other critically important aspects of student achievement, and, at worst, they completely ignore that information. If institutions wish to rank students, then differentiated grades provide a more comprehensive analysis than present methods based purely on medical knowledge and skills. Of course, given the wealth of additional information, class rank calculations may no longer be necessary.

As noted previously, faculty may feel unable to defend scores that are based primarily on subjective judgments. Ironically, this problem has led to many faculty being unable to justify a failing grade for students that possess sufficient medical knowledge, but severe shortcomings in professional attitudes and behaviors. As a result, some students continue to navigate the medical education pipeline when they should not. Differentiated grading is more defensible because the specific criteria that the student failed are clearly articulated. For students that accumulate a number of poor professionalism grades (e.g., grades based on attitudinal and behavioral criteria), institutions would have much stronger leverage for dismissing a student or not recommending a student for advancement, despite exceptional medical knowledge and skill performance.

\section{The Product, Process, and Progress Grading Model}

A proven differentiated grading model from K-12 education involves assigning separate grades based on three distinct criteria: product, process, and progress $[5,6]$. In short, this grading schema provides insights on what students know (product), how they arrived at their grade (process), and how much they have improved over time (progress). This grading schema can be extended easily to medical education. For example, product grades may involve typical intellectual outcomes, such as performance on various knowledge and skill examinations. Process grades may focus on attitudinal and behavioral measures that comprise definitions of professionalism. Progress grades may simply involve a plus, minus, or equal sign to denote changes in student performance from the beginning of a course or clerkship until its conclusion. Recent developments in medical education including entrustable professional activities (EPAs), milestones, and progress testing also would be very compatible with the product, process, and progress criteria. For example, knowledge- and skillbased EPAs could comprise the product criteria, behaviorbased EPAs could comprise the process criteria, and the (longitudinal) stages through which students navigate could comprise the progress criteria. More examples of acceptable evidence for each grading criteria are presented in Table 1. Adopting a differentiated grading model such as the product, process, and progress approach can help clarify the meaning of grades and greatly improve their communicative value.

Many faculty may be skeptical of differentiated grading because it may appear to require additional effort. However, those faculty that have implemented this procedure in the $\mathrm{K}-12$ arena indicate that grading is easier and requires less work [7]. In short, faculty continue to gather the same evidence on student learning as they normally would, but no longer have to worry about developing and defending a weighting schema that combines evidence into a single grade. As a result, faculty are now able to avoid the pitfalls of having

Table 1 Examples of acceptable evidence for product, process, and progress criteria

\begin{tabular}{|c|c|c|}
\hline Product & Process & Progress \\
\hline $\begin{array}{l}\text { Results from various knowledge } \\
\text { and skill assessments (e.g., exams, } \\
\text { EPAs, milestones, clinical } \\
\text { performance, major projects, laboratory } \\
\text { projects, OSCEs, oral presentations, etc.) }\end{array}$ & $\begin{array}{l}\text { Results from various attitudinal and } \\
\text { behavioral assessments (e.g., attendance, } \\
\text { participation, team work, punctuality, effort, } \\
\text { timeliness, dependability, and other aspects } \\
\text { of professional behavior) }\end{array}$ & $\begin{array}{l}\text { Results from assessments that measure } \\
\text { change over time (e.g., longitudinal exams, } \\
\text { progress tests, pre- vs. post-tests, etc.) }\end{array}$ \\
\hline
\end{tabular}


to defend the appropriateness or fairness of a particular weighting strategy.

Many residency programs now require more extensive student information to make better informed decisions about the suitability of candidates [8]. Others have noted the inconsistent use of grades and calculation methods across institutions [9]. Further, concerns of grade inflation are widespread as faculty have few options other than to assign high marks given the limitations involved with assigning a single grade [10]. In all these instances, differentiated grading can help resolve these issues. In particular, differentiated grades provide consumers a greater breadth of information about students, including student attitudes and behaviors, and provide faculty additional options to report grades, which increases grading variation.

\section{Conclusions}

Medical education is in dire need of improved grading practices. At present, the predominant use of amalgamated grades leaves much to be desired in terms of grade meaning and clarity, and many find these grades difficult to defend in instances in which factors beyond medical knowledge are of concern. Furthermore, consumers of these grades often feel mislead when encountering students that are sufficiently knowledgeable, but insufficiently professional. Institutions that provide misleading grades are at significant risk of great harm to both the reputation of the institution and its alumni. Differentiated grades, on the other hand, help clarify the meaning of grades, improve their communicative value, and help reduce the potential for negative unintended consequences that may result from grade inferences.

\section{References}

1. DeSantis N. University can deny a medical degree over lack of 'Professionalism,' court rules. 2015. From http://chronicle.com/ blogs/ticker/university-can-deny-a-medical-degree-over-lack-ofprofessionalism-court-rules/92935. Accessed on February 6, 2015.

2. Chen, PW. Why failing med students don't get failing grades. The New York Times. 28 Feb. 2013. The New York Times Health/ Science Blog. Accessed February 6, 2015.

3. Messick S. Validity. In: Linn RL, editor. Educational Measurement. 3rd ed. New York: Macmillan Publishing Co; 1989. p. 13-103.

4. Royal KD, Puffer JC. The consequential validity of ABFM examinations. J Am Board Fam Med. 2014;27(3):430-1.

5. Guskey TR. Making high school grades meaningful. Phi Delta Kappan. 2006;87(9):670-6.

6. Guskey TR. Grading policies that work against standards... and how to fix them. In: Guskey TR, editor. Practical solutions to serious problems in standards-based grading. Thousand Oaks: Corwin; 2009. p. 26.

7. Guskey TR, Swan GM, Jung LA. Parents' and teachers' perceptions of standards-based and traditional report cards. Paper presented at the Annual Meeting of the American Educational Research Association, New Orleans, LA, April, 2011.

8. Benzinger R. From the desk of the program director: show me the rankings! J Grad Med Educ. 2014;6(3):413-4.

9. Alexander EK, Osman NY, Walling JL, Mitchell VG. Variation and imprecision of clerkship grading in U.S. medical schools. Acad Med. 2012;87(8):1-7.

10. Fazio SB, Papp KK, Torre DM, Defer TM. Grade inflation in the internal medicine clerkship: a national study. Teach Learn Med. 2013;25:71-6. 